\title{
๖Applying a Physically Based Blowing Snow Diagnostic Parameterization to Improve Wintertime Visibility Forecasts in the WRF Model
}

\author{
Theodore W. LeTCher, ${ }^{\mathrm{a}, \mathrm{b}}$ SANDRA L. LeGrand, ${ }^{\mathrm{a}, \mathrm{b}}$ AND Christopher Polashenski ${ }^{\mathrm{a}, \mathrm{b}}$ \\ ${ }^{a}$ Cold Regions Research and Engineering Laboratory, Hanover, New Hampshire \\ ${ }^{\mathrm{b}}$ Engineer Research and Development Center, U.S. Army Corps of Engineers, Vicksburg, Mississippi
}

(Manuscript received 2 July 2020, in final form 7 December 2020)

\begin{abstract}
Blowing snow presents substantial risk to human activities by causing severe visibility degradation and snow drifting. Furthermore, blowing snow presents a weather forecast challenge since it is not generally simulated in operational weather forecast models. In this study, we apply a physically based blowing snow model as a diagnostic overlay to output from a reforecast WRF simulation of a significant blowing snow event that occurred over the northern Great Plains of the United States during the winter of 2019. The blowing snow model is coupled to an optics parameterization that estimates the visibility reduction by blowing snow. This overlay is qualitatively evaluated against false color satellite imagery from the GOES-16 operational weather satellite and available surface visibility observations. The WRF-simulated visibility is substantially improved when incorporating blowing snow hydrometeors. Furthermore, the model-simulated plume of blowing snow roughly corresponds to the blowing snow plumes visible in the satellite imagery. Overall, this study illustrates how a blowing snow diagnostic model can aid weather forecasters in making blowing snow visibility forecasts, and demonstrates how the model can be evaluated against satellite imagery.

SIGNIFICANCE STATEMENT: We wanted to investigate improvements in forecast near-surface visibility by attaching a physically based blowing snow model to the Weather Research and Forecast Model. We show that the inclusion of the blowing snow model greatly improved the visibility forecast across the region during a widespread blowing snow event that occurred over the north-central United States in February 2019. This model was able to predict the general spatial coverage and timing of the whiteout conditions associated with the event. Furthermore, the blowing snow diagnostic is relatively straightforward to implement into existing weather models and can aid weather forecasters in identifying blowing snow risks.
\end{abstract}

KEYWORDS: Optical properties; Snow cover; Visibility; Numerical weather prediction/forecasting; Atmosphere-land interaction

\section{Introduction}

Blowing snow presents a substantial hazard to human activities in cold regions. It causes localized severe reductions to visibility near the ground, often with little warning, and often under clear skies. Blowing snow also results in snow drifting, which presents additional hazards to motor vehicle transportation. Currently, standard numerical weather prediction (NWP) models estimate horizontal visibility from the modelsimulated hydrometeor mass concentrations (e.g., Stoelinga and Warner 1999). Critically, the current visibility diagnostic used in U.S.-based operational weather forecast models does not include blowing snow hydrometeors. Rather, blowing snow forecasts are typically determined by empirical ingredients based models (e.g., Baggaley and Hanesiak 2005) and local forecaster experience. In this study, we combine physically based parameterizations for snow saltation and turbulent suspension typically applied to snow-transport models, with an optics parameterization rooted in Mie theory to simulate the

¿ Denotes content that is immediately available upon publication as open access.

Corresponding author: Theodore Letcher, ted.letcher@gmail.com impacts of blowing snow on near-surface visibility. This parameterization is demonstrated for a reforecast WRF simulation of a significant blowing snow event that affected the north-central United States on 24 February 2019. This event was notable for its widespread spatial coverage, severity, and human impacts. For instance, this event led to widespread interstate closures in South Dakota, Minnesota, and Wisconsin. Furthermore, this event was a rare instance where blowing snow was observable by operational weather satellites, providing an additional observational dataset to compare the model to (Kennedy and Jones 2020).

Wind-driven particle entrainment (sediment or snow) occurs due to one or more subprocesses, including direct aerodynamic entrainment, saltation, aggregate disintegration and/or fragmentation (Bagnold 1941; Owen 1964; Kok et al. 2012). Larger particles on the order of $60-100 \mu \mathrm{m}$ tend to dislodge first (aerodynamic entrainment). Once lofted, these larger particles undergo the saltation process, where mobilized particles too heavy to remain airborne get accelerated by the airstream and fall back toward the land surface with ballistic trajectories. The resultant collision impacts at the surface can dislodge additional particles into motion, break apart embedded or saltating aggregates, or produce finer particles prone to atmospheric suspension through fracturing and spalling. Although there are many commonalities between wind-blown 


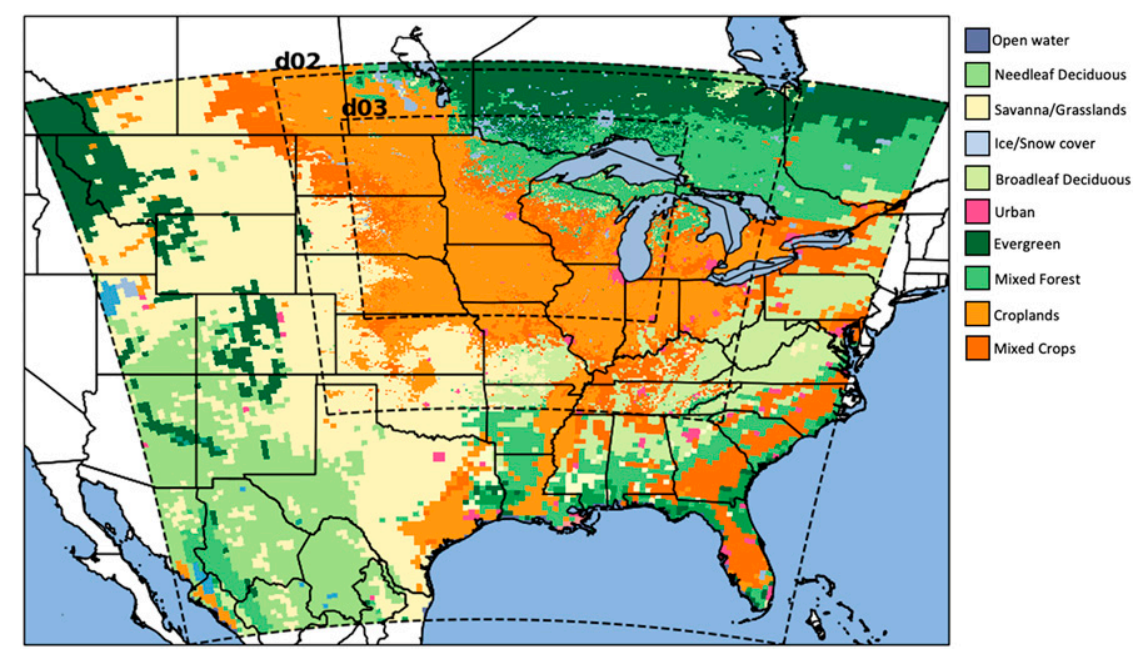

FIG. 1. WRF domains illustrating the WRF land cover classification.

sediment and snow transport with respect to energy availability, momentum transfer, and fracturing processes (e.g., Anderson and Hallet 1986; Pomeroy and Gray 1990; Raupach 1992; Kok 2011; Walter et al. 2012), characterizing snow transport can be quite challenging due to the complicating effects of snow particle geometry and snowpack erodibility state on fragmentation dynamics and particle mobilization (e.g., Li and Pomeroy 1997; Comola et al. 2017; Paterna et al. 2016).

Physically based snow transport models typically divide blowing snow into two distinct steps: saltation and turbulent suspension of particles from the saltation layer into the atmospheric boundary layer (e.g., Pomeroy et al. 1993; Liston and Sturm 1998; Déry and Yau 1999; Vionnet et al. 2014; Kang et al. 2018). In numerical models, the saltation process is typically parameterized as a function of the model-simulated friction speed, and turbulent suspension is then related to saltation through additional empirical formulas (e.g., Pomeroy and Male 1992; Pomeroy et al. 1993; Liston and Sturm 1998). In general, these models are used to simulate the redistribution of snow in complex terrain and enhanced snow sublimation within a snow model or land surface model (e.g., Liston and Sturm 1998; National Operational Hydrologic Remote Sensing Center 2004; Liston et al. 2007). However, it is possible to adapt specific components of these models for weather forecast applications to improve visibility forecasts in affected regions.

Once suspended in the boundary layer, blowing snow is generally thought to be made up of small spheroid particles (mean particle radius between $10 \mu \mathrm{m} \leq r \leq 80 \mu \mathrm{m}$ ) which are described using a gamma size distribution (e.g., Pomeroy and Male 1988; Huang et al. 2008; Gordon and Taylor 2009). These smaller particles are especially effective at scattering visible light, and therefore blowing snow has more substantial impacts on near-surface visibility than snow precipitation, which is typically comprised of snow particle aggregates with mean radii greater than $2 \mathrm{~mm}$. Therefore, blowing snow requires its own hydrometeor category and extinction coefficient in a visibility diagnostic, as simply adding the blowing snow mass to the snow hydrometeor concentration in standard visibility calculation is insufficient. In this paper, we explore the benefit of using physically based snow transport and blowing snow optics parameterizations to enhance model-simulated surface visibility forecasts.

\section{Data and methods}

\section{a. WRF Model configuration}

The Weather Research and Forecast (WRF) Model, version 4.1 (Skamarock et al. 2019) was used to simulate a widespread and high-impact blowing snow event that occurred on 24 February 2019 over the north-central United States.

WRF is a nonhydrostatic fully compressible Eulerian atmospheric model that incorporates several advanced physical parameterizations to simulate atmospheric radiation, cloud microphysics, and the effects of subgrid motion within the boundary layer. WRF V4.1 uses the Arakawa-C grid and a stretched terrain following hybrid sigma-pressure vertical coordinate. In this study, the WRF domain was configured with a triplenested 3-to-1 ratio telescoping configuration with a high-resolution $(\Delta x=3 \mathrm{~km})$ nested domain centered over the north-central United States (Fig. 1). The WRF atmospheric model component was coupled to the Noah-MP LSM (Niu et al. 2011). Noah-MP contains a multilayer snow model that allows up to three snow layers and a sophisticated forest canopy parameterization. WRF was initialized and forced on the lateral boundaries of the parent $(27 \mathrm{~km})$ domain every $6 \mathrm{~h}$ using data from Rapid Refresh (RAP) model analysis. The WRF Model was initialized at 0000 UTC 22 February 2019, giving the model two days of spinup prior to the start of the event. The spinup period allowed ample time for the model to adjust to the initial conditions, and for the model to produce the snowfall that preceded the blowing snow event.

Additional relevant WRF parameterization choices are provided in Table 1.

\section{b. Blowing snow visibility model}

Generally, blowing snow models treat saltation and turbulent suspension as distinct processes linked through empirical 
TABLE 1. WRF Model physical parameterizations.

\begin{tabular}{llll}
\hline \hline \multicolumn{1}{c}{ Domain } & \multicolumn{1}{c}{$\Delta x=27 \mathrm{~km}$} & \multicolumn{1}{c}{$\Delta x=9 \mathrm{~km}$} & \multicolumn{1}{c}{$\Delta x=3 \mathrm{~km}$} \\
\hline Radiation & RRTMG (Iacono et al. 2008) & RRTMG & \multicolumn{2}{c}{ RRTMG } \\
Microphysics & Thompson (Thompson et al. 2008) & Thompson & Thompson \\
Cumulus & Kain-Fritsch (Kain 2004) & Kain-Fritsch & None \\
Boundary layer & MYNN 2.5 TKE (Nakanishi and Niino 2009) & MYNN 2.5 TKE & MYNN 2.5 TKE \\
Surface layer & MYNN & MYNN & MYNN \\
\hline
\end{tabular}

and semiempirical formulas. Typically, these models compute saltation $Q_{s}$ as a streamwise mass flux $\left(\mathrm{kg} \mathrm{m}^{-1} \mathrm{~s}^{-1}\right)$ based primarily on the difference between the surface friction speed $u_{*}$ and some minimum threshold friction speed $u_{*_{t}}$ that must be overcome before snow particles resting on the surface become mobile (e.g., Pomeroy and Gray 1990). The $u_{*_{t}}$ parameter typically ranges from 0.15 to $1.0 \mathrm{~m} \mathrm{~s}^{-1}$, and is a convenient representation of the snow surface erodibility. In nature, $u_{*_{t}}$ is largely determined by the strength of the bonds between snow particles resting on the snow surface and is a complicated function of particle size and shape, as well as bulk snow surface characteristics such as temperature and density (e.g., Schmidt 1982). While there are several parameterizations for $u_{*_{t}}$ in the literature (e.g., Li and Pomeroy 1997; Liston et al. 2007; Vionnet et al. 2012; He and Ohara 2017), we chose to use a constant value of $0.2 \mathrm{~m} \mathrm{~s}^{-1}$ for simplicity and clarity. This value of $u_{* t}$ is indicative of a highly erodible snowpack, which is appropriate for this case, as this blowing snow event occurred under cold conditions immediately following a fresh snowfall.

In this study, $Q_{s}$ is computed following the semiempirical formula from Pomeroy and Gray (1990):

$$
Q_{s}=\frac{0.68}{u_{*}}\left(\frac{\rho_{a}}{g}\right) u_{*_{t}}\left(u_{*}^{2}-u_{*_{t}}^{2}\right),
$$

where $\rho_{a}$ is the surface air density, $g$ is the gravitation constant, and $u_{*}$ is the friction speed. We chose to use this parameterization because it is simple to implement and, in contrast to other $Q_{s}$ parameterizations that are based on modified soil saltation schemes, it was derived directly from observations of blowing snow.

In this study, the friction speed used in the saltation function is derived using neutrally stable log wind profile applied to the WRF-simulated $10-\mathrm{m}$ wind speed:

$$
u_{*}=U_{10 \mathrm{~m}} \frac{\kappa}{\ln \left(10 / z_{0}\right)},
$$

where $U_{10 \mathrm{~m}}$ is the $10-\mathrm{m}$ wind speed, $\kappa$ is Von Kármán's constant (0.4), and $z_{0}$ is the surface roughness for snow $(0.002 \mathrm{~m})$. We chose not to use the WRF-simulated $u_{*}$ because the model roughness lengths for forested and urban land cover classifications are not representative of the surface roughness, but

TABLE 2. GOES-16 channels used to generate false color imagery.

\begin{tabular}{ccc}
\hline \hline GOES-16 channel No. & Central wavelength & Color channel \\
\hline 3 & $0.86 \mu \mathrm{m}$ & $\mathrm{R}$ \\
5 & $1.6 \mu \mathrm{m}$ & $\mathrm{G}$ \\
$(7-13)$ & $(3.9-10.3) \mu \mathrm{m}$ & $\mathrm{B}$ \\
\hline
\end{tabular}

rather the combined roughness of trees and buildings, which leads to unrealistically high $u_{*}$ values for these land categories.

To connect the saltation flux to the blowing snow mass concentration at $2 \mathrm{~m}$ above ground level (AGL), we use the steady state blowing snow model described in Pomeroy and Male (1992):

$$
c(z)=C_{r} \exp \left\{-1.55\left[\left(0.05628 u_{*}\right)^{-0.544}-z^{-0.544}\right]\right\},
$$

where $c(z)$ is the blowing snow concentration $\left(\mathrm{kg} \mathrm{m}^{-3}\right)$ at height $z$ in meters, and $C_{r}$ is a reference level blowing snow concentration computed from the saltation flux $Q_{s}$.

From a numerical modeling perspective, the key advantage of using the function from Pomeroy and Male (1992) is that it was derived assuming steady-state conditions, implying that sublimation occurring within the turbulent suspension layer

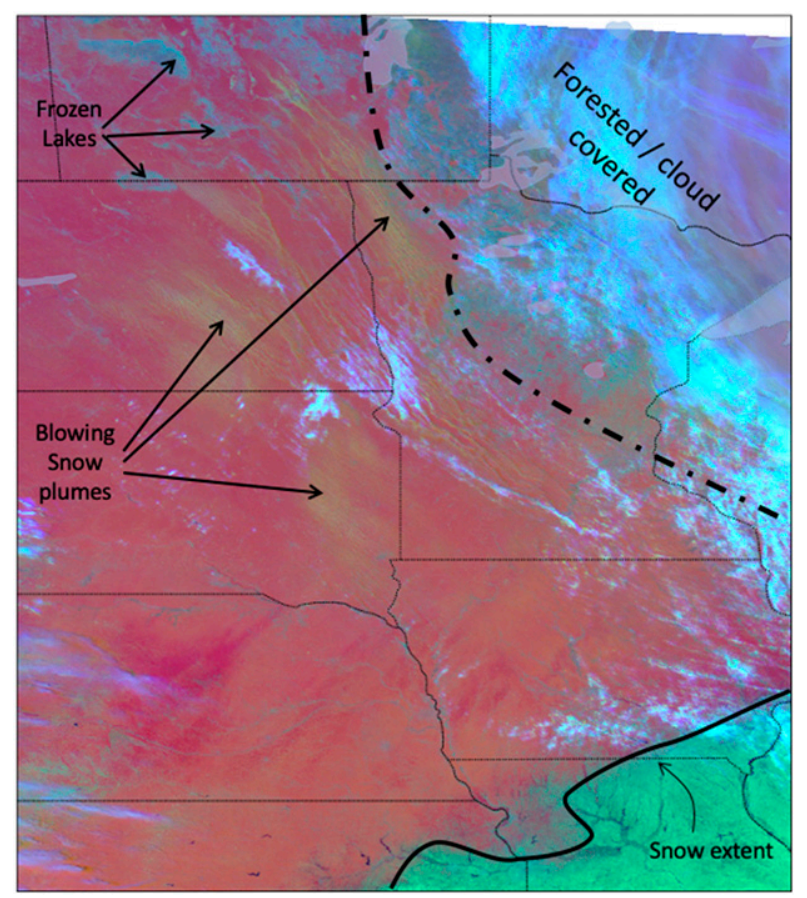

FIG. 2. Example false color satellite image from the GOES-16 operational weather satellite with annotations provided as guidance. Pink coloring is indicative of snow cover, the cyan and bluish colors show frozen water bodies and forested regions, aquamarine colors in the southeast corner of the image are indicative of snow free ground, and the bright white colors show clouds. Blowing snow plumes are indicated by the neon green streaks oriented from northwest to southeast. 

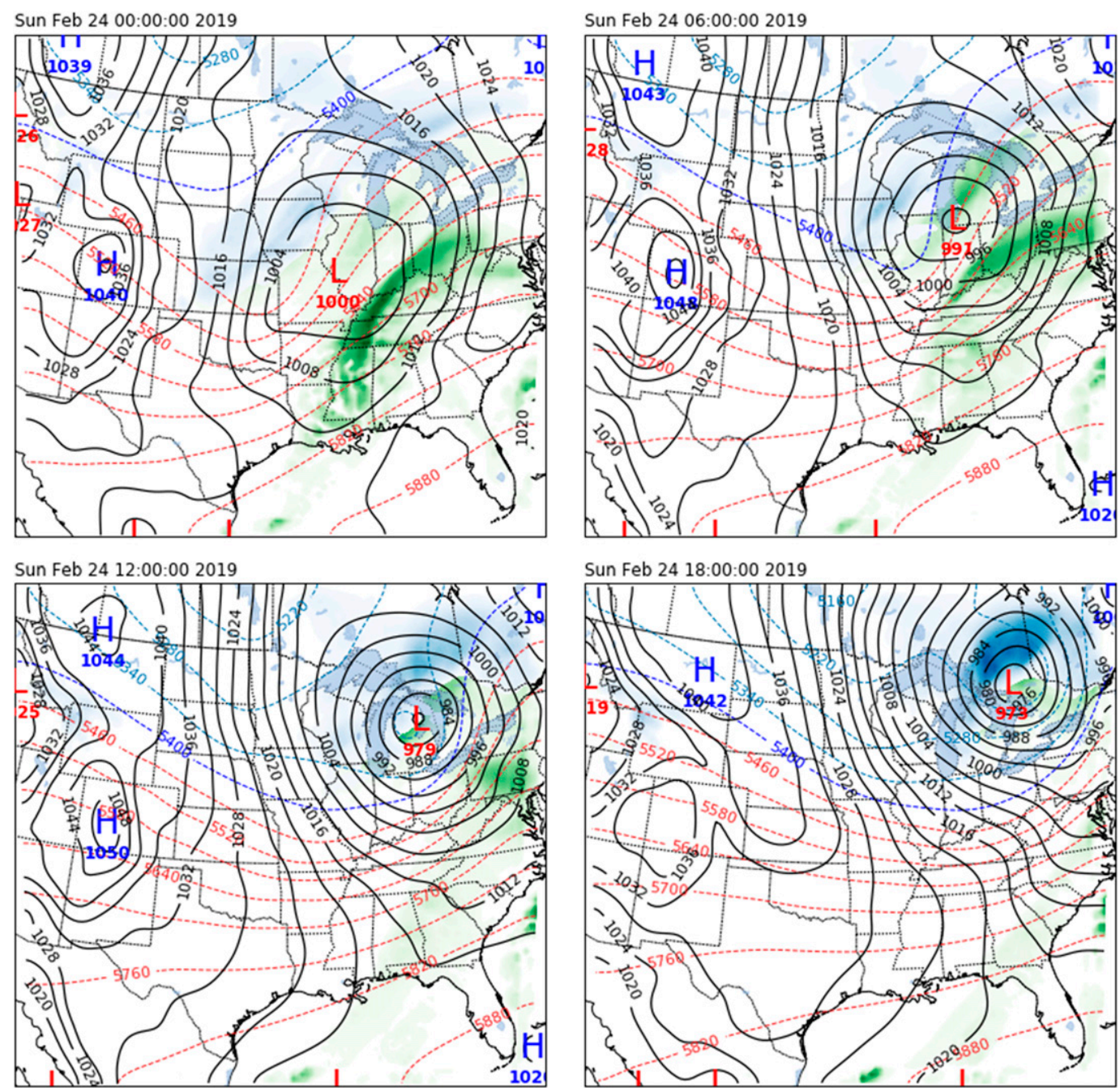

FIG. 3. Synoptic overview of the surface meteorology from the WRF simulation. Mean sea level pressure and 1000-500-hPa thickness (contours) and rain (shaded green) and snow (shaded blue) precipitation is shown for four times throughout the blowing snow event illustrating the synoptic evolution of the event.

(which serves as a sink, eliminating suspended particles) is accounted for in the empirical function and does not need to be included separately within the diagnostic framework.

To compute $C_{r}$ we use the formula presented in Vionnet et al. (2014):

$$
C_{r}=\frac{Q_{s}}{u_{p}} \frac{\lambda g}{u_{*}^{2}} \exp \left(-\frac{\lambda z_{r} g}{u_{*}^{2}}\right),
$$

where $\lambda$ is a dimensionless constant equal to $0.45, u_{p}$ is the mean particle speed $\left(u_{p}=1.6 u *_{t}\right)$, and $z_{r}$ is the height at the top of the saltation layer given as in Liston and Sturm (1998):

$$
z_{r}=1.6 \frac{u_{*}^{2}}{2 g}
$$

Finally, 2-m visibility $V$ is computed from $c(z)$ following the form described in Pomeroy and Male (1988). This parameterization assumes that the blowing snow particle size distribution is well described by a gamma distribution and combines the Koschmieder formula for visibility (Horvath 1971) with Mie scattering approximations for visible and near-IR (NIR) wavelengths:

$$
V=\frac{5.217 \bar{r} \rho_{p}}{c(z) \overline{Q_{\mathrm{ext}}} c_{\alpha}},
$$

where $\bar{r}$ is the mean particle radius (in meters) and $\overline{Q_{\text {ext }}}$ is the extinction coefficient given as a function of $\bar{r}$ :

$$
\overline{Q_{\mathrm{ext}}}=1.82 \bar{r}^{-0.011} \text {. }
$$

The term $c_{\alpha}$ is the gamma-distribution shape-correction factor based on the gamma-function shape parameter $\alpha$ :

$$
c_{\alpha}=\frac{(\alpha+1) ! \alpha}{(\alpha+2) !}
$$



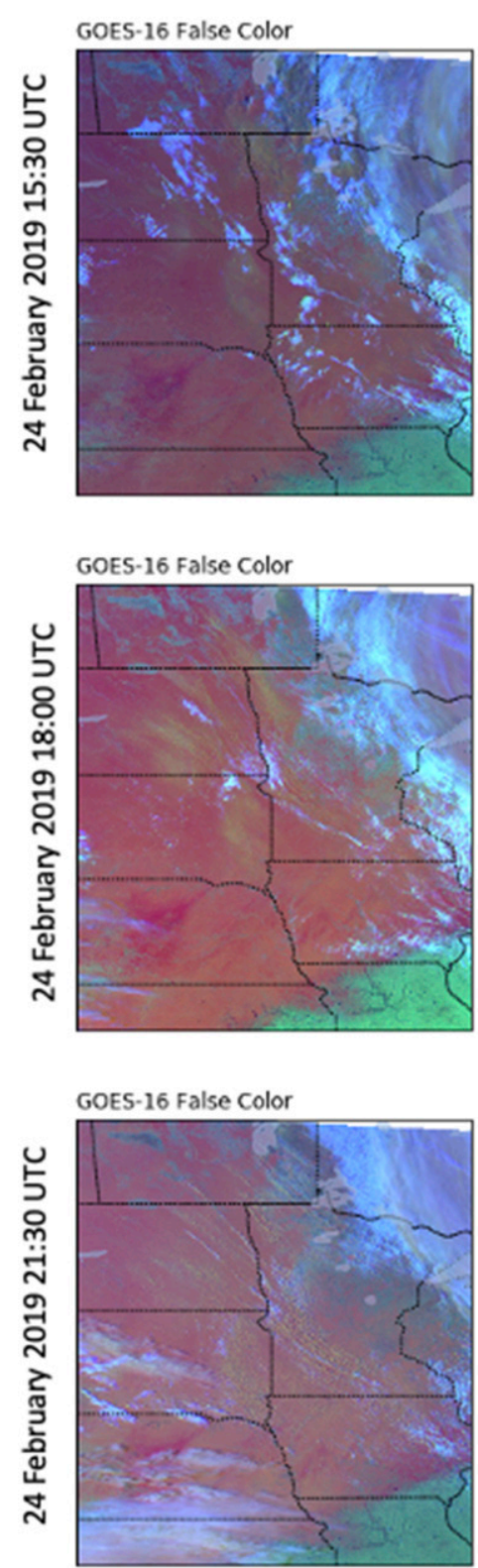
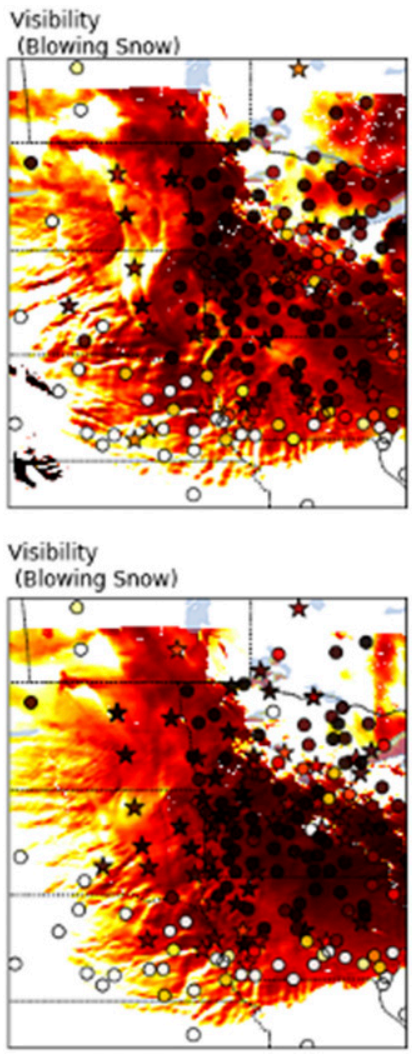

Visibility

(Blowing Snow)

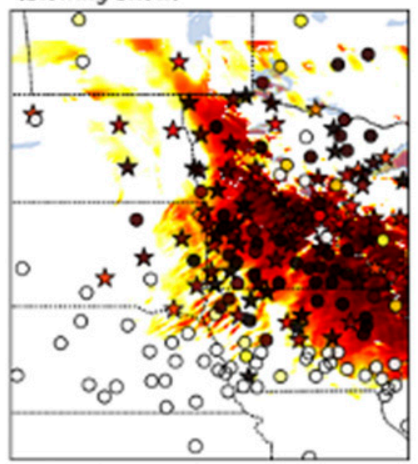

Visibility

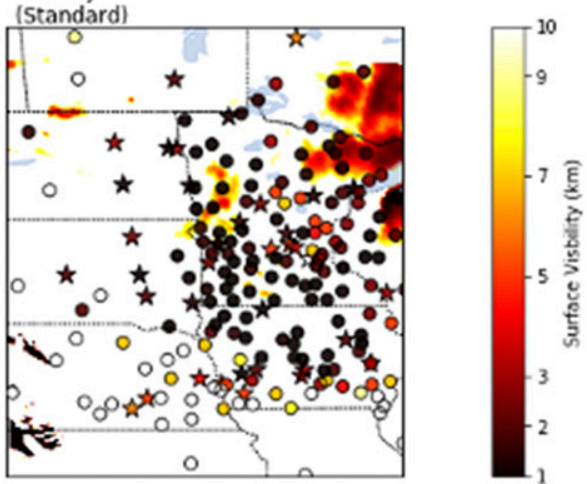

Visibility

(Standard)

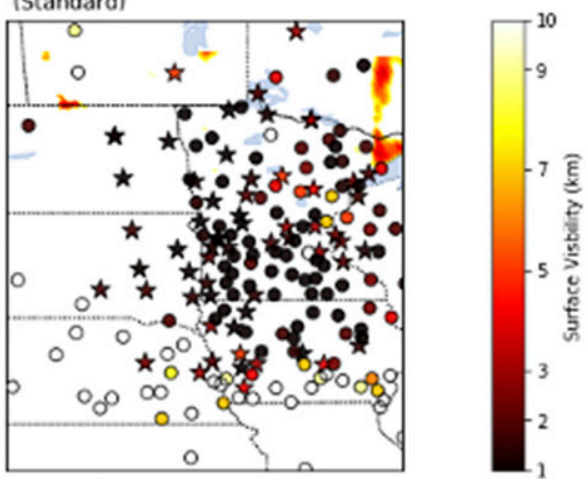

Visibility

(Standard)
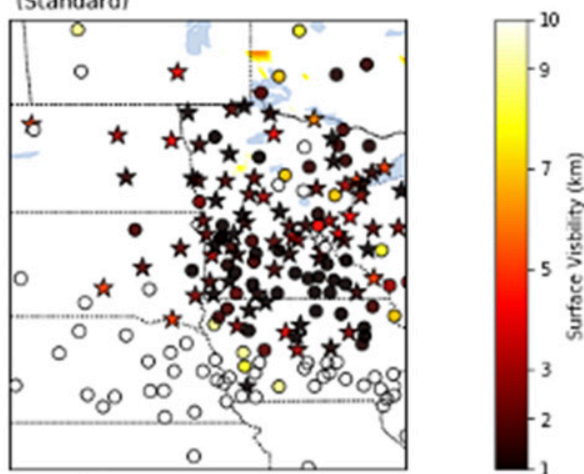

FIG. 4. Comparison of GOES-16 false color imagery, simulated visibility from the innermost domain $(\Delta x=3 \mathrm{~km})$ with and without blowing snow hydrometeors at three times throughout the blowing snow event. Markers show the observed surface visibility. Starred markers indicate reports of blowing snow (BLSN) in the METAR.

It is common to assume that both $\bar{r}$ and $\alpha$ vary with height such that the particle size becomes smaller, and the distribution becomes narrower (e.g., Liston and Sturm 1998; Brown and Pomeroy 1989; Nemoto and Nishimura 2004; Nishimura and Nemoto 2005). For simplicity, we assume values of $\bar{r}=30 \mu \mathrm{m}$ and $\alpha=15$. These values fall well within the common range of values reported at $2 \mathrm{~m}$ AGL in the literature (e.g., Mellor 1965; Huang et al. 2008). To approximate the extinction coefficient for blowing snow $\beta$, the Koschmieder relationship is inverted:

$$
\beta=\frac{3.912}{V} \text {. }
$$

The term $\beta$ is then added to the extinction coefficients for the hydrometeors in the visibility formula described in Stoelinga and Warner (1999) to generate a combined visibility diagnostic.

\section{c. GOES-16 false color imagery}

In general, it is difficult to discriminate blowing snow using passive satellite observations for the following reasons: 1) blowing snow occurs near the ground and is often obscured by overhead clouds, and 2) blowing snow is challenging to distinguish from snow covered surfaces in the visible and IR 
channels. However, false color imagery constructed using visible, NIR, and IR channels can be useful in qualitatively assessing the spatial extent of large blowing snow events during daylight hours free of overhead cloud obstructions (Palm et al. 2011; Kennedy and Jones 2020).

This event was easily visible in GOES-16 false color imagery across the region due the fact that 1) there were no overhead clouds obstructing the surface, and 2) strong cold air advection and boundary layer winds organized blowing snow into mesoscale horizontal convective rolls, which helped distinguish the blowing snow from the snow surface (Kennedy and Jones 2020). To qualitatively evaluate the simulated spatial extent of the blowing snow, we generated false color imagery from four GOES-16 channels using the channels described in Kennedy and Jones (2020). The GOES-16 data were accessed through the NOAA Comprehensive Large Array Data Stewardship System (NCEI 2017). The specific channels, center wavelengths, and color channels are shown in Table 2. To enhance the appearance of the blowing snow within the satellite imagery, tuning constants were applied to each of the three RGB channels. In addition, a time-of-day-dependent gamma correction and additional contrast adjustments were made to the images. An annotated example of this imagery is given in Fig. 2.

\section{d. Surface observations}

Surface weather observations from the Automated Surface Observation System (ASOS) network, are used to evaluate the blowing snow diagnostic. Specifically, we use reports of blowing snow, and surface visibility observations. While explicit reports of blowing snow can be helpful, they are imperfect, as blowing snow is frequently misclassified as a different phenomenon (e.g., haze). Fortunately, this event occurred underneath clear skies with low relative humidity, and in most instances any surface visibility degradation was likely due to blowing snow. These data are archived on a server managed by Iowa Environmental Mesonet (IEM2020).

\section{Results}

\section{a. Synoptic overview and model evaluation}

The widespread blowing snow event that occurred on 24 February 2019 was caused by the interaction between a continental polar air mass that progressed south into the northern interior United States and the passage of a strong midlatitude cyclone that traversed southwest to northeast across the central United States between 0000 and 1200 UTC 24 February. Figure 3 illustrates the evolution of this event by showing mean sea level pressure (MSLP), precipitation and 1000-500-hPa thickness at 6-hourly intervals between 0000 UTC 24 February and 0000 UTC 25 February 2019. At 0000 UTC 24 February, a defined area of low pressure was organized over Missouri and light to moderate amounts of snow fell across the central United States, particularly along the Nebraska-South Dakota border and throughout southeast Minnesota. As the storm tracked north and east of the region it strengthened, attaining a minimum MSLP of approximately $975 \mathrm{hPa}$ around 1800 UTC 24 February. At this time, the storm

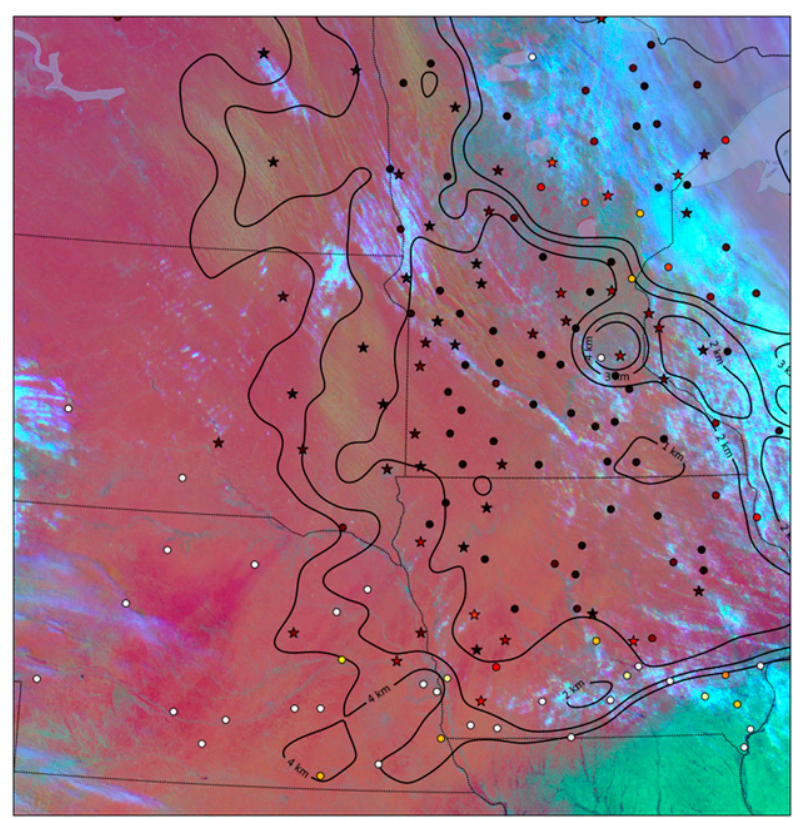

FIG. 5. GOES-16 false color image at 1800 UTC 24 Feb with WRF-simulated visibility with blowing snow hydrometeors contoured. Markers are shown as in Fig. 4.

was centered over Michigan's Upper Peninsula, and the snowfall had largely ceased to the west of the MinnesotaWisconsin border. As the polar air mass (marked by the broad area of high pressure centered over the Montana-Canada border) progressed south following the departing cyclone, clear skies rapidly developed across the north-central United States beginning around 1200 UTC 24 February. The tight pressure gradient between the strengthening cyclone to the east of the region and the encroaching area of high pressure $($ MSLP $>1040 \mathrm{hPa}$ ) to the west, in combination with the freshly fallen snow led to a broad region of high winds with widespread blowing and drifting snow that persisted for a 12-h period between approximately 1200 UTC 24 February and 0000 UTC 25 February 2019. During this event, over 70 surface weather stations in Minnesota, South Dakota, North Dakota, and Iowa recorded visibilities less than $1 \mathrm{~km}$, with several stations recording sub-1-km visibility for greater than four hours.

We first evaluated the WRF simulation by comparing MSLP to available surface analysis from the Weather Prediction Center. In general, WRF was able to simulate the evolution of the event with good fidelity, in particular the strength and progression of the cyclone throughout the event was well simulated. A comparison between the model simulated and observed 10-m wind speeds throughout the blowing snow event showed generally good agreement, with WRF correctly simulating the onset and cessation of high winds at the beginning and end of the event. However, WRF showed a general tendency to modestly over estimate wind speeds observed to be below $6 \mathrm{~m} \mathrm{~s}^{-1}$ throughout the event (not shown). Since WRF was able to simulate the synoptic evolution of the event, as well as the strong wind speeds that drove the event, we conclude 

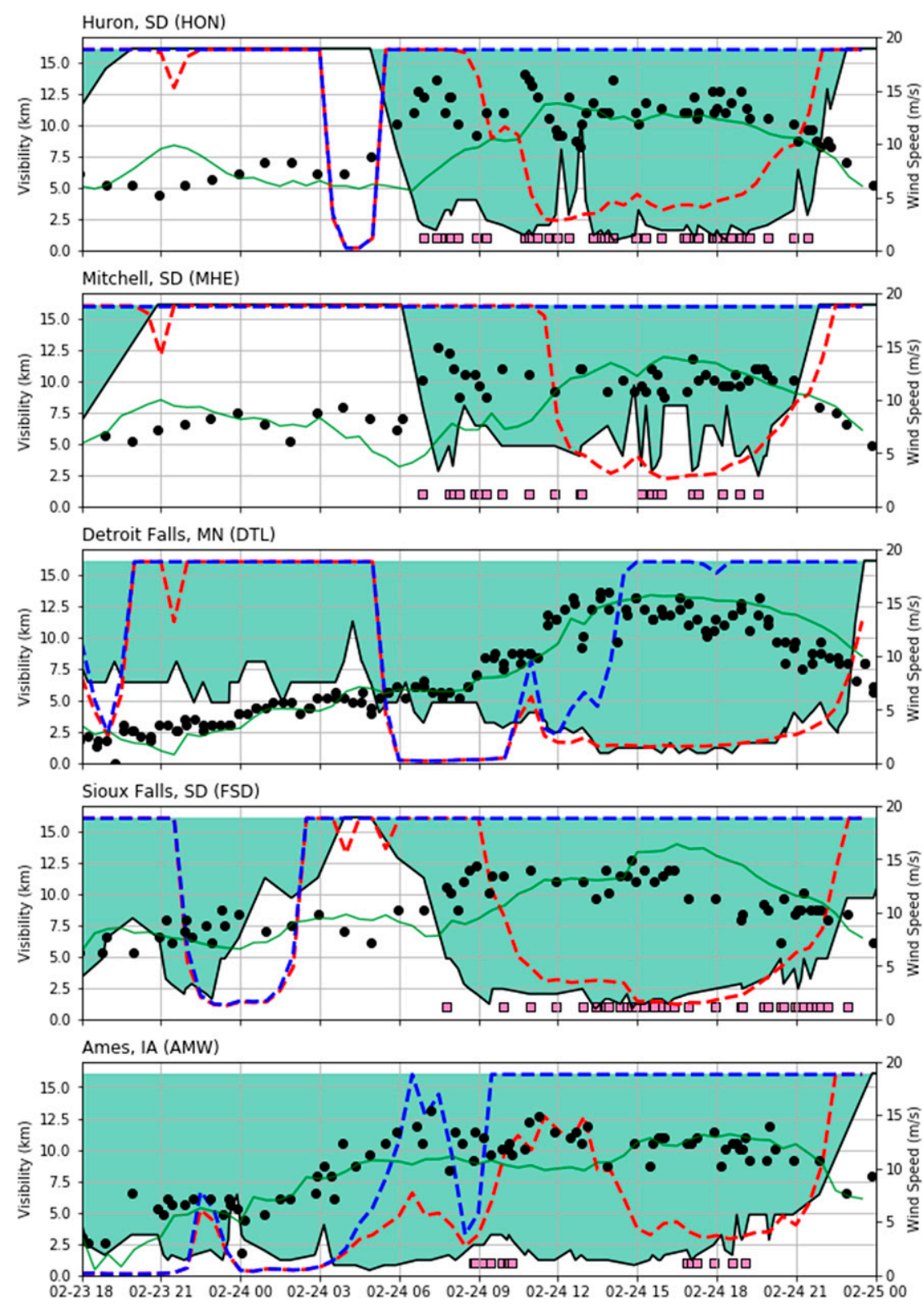

FIG. 6. Time series of observed visibility (left $y$ axis: teal shading) and wind speed (right $y$ axis: black markers) at five surface weather stations throughout the domain. Reports of blowing snow in the observations are indicated by pink squares. Simulated visibility and wind speed are overlaid as indicated by the legend and scaled by each respective $y$ axis.

that it is appropriate to assess the diagnostic blowing snow visibility model as applied to the WRF output.

\section{b. Evaluation of blowing snow visibility}

The blowing snow diagnostic is qualitatively evaluated by comparing GOES-16 false color imagery alongside simulated 2-m visibility with and without blowing snow hydrometeors from the $3-\mathrm{km}$ resolution domain $(\mathrm{d} 03)$ for three times throughout the event (Fig. 4). To further evaluate the model, visibility observations from available surface stations are overlaid on the simulated visibility. The spatial extent of the simulated reduced visibility broadly matches the spatial coverage of the blowing snow plumes in the GOES-16 imagery. Furthermore, the WRF-simulated visibility more accurately reflects the surface visibility observations when blowing snow hydrometeors are considered in the model. In contrast, the standard model output visibility shows no visibility reduction across the region. This is unsurprising, as both the GOES-16 imagery and the model show cloud and precipitation-free conditions during these times. Notably, several stations reporting severely degraded visibility are not reporting blowing snow, despite the accompanying evidence suggesting that 
blowing snow is the cause of the visibility degradation. Further investigation indicated that the majority of these stations were reporting haze. We speculate that uncertainty in the automated algorithms used to discriminate blowing snow from other hydrometeors failed to detect many instances of blowing snow, resulting in a default haze classification based on the measured visibility and relative humidity. No attempt is made to correct these observations in this analysis, however the relatively high number of misclassified blowing snow stations suggests that, in general, automated blowing snow reports should be treated with skepticism without accompanying datasets.

A more detailed comparison between the WRF-simulated visibility and the GOES-16 imagery at the peak of the event shows remarkably good agreement. In particular, the western edge of the simulated plume coincides with the western edge of the plumes in the GOES-16 imagery and surface observations (Fig. 5).

The coverage of the event remained constant throughout much of the day in this region, but started to taper off from west to east in the simulation after 2100 UTC. Unfortunately, it is difficult to evaluate the event termination using the GOES-16 imagery due to nightfall over the region. Additional focus on surface station data is used to evaluate the simulated event termination.

To evaluate the model's ability to simulate the timeevolution of the event, time series of observed and simulated visibility are presented for five selected surface stations spread out across South Dakota, Minnesota, and Iowa (Fig. 6). At all of the selected stations, the model-simulated visibility matched the observations significantly better when blowing snow hydrometeors were considered. In general, the timing of the blowing snow event was well captured by the model. Furthermore, the majority of instances where the blowing snow visibility did not match the observed visibility can likely be attributed to underestimates in the model-simulated wind speed as opposed to the blowing snow model components. For instance, simulated wind speed and visibility are under and overestimated, respectively, at the onset of the blowing snow event at Honor and Mitchell, South Dakota. Furthermore, observed blowing snow reports generally match where the blowing snow visibility is most different from the standard visibility at all stations (Fig. 6).

This analysis is extended by computing the time-mean visibility at all stations in North Dakota, South Dakota, Minnesota, and Iowa between 1200 UTC 24 February and 0000 UTC 25 February, and generating kernel density estimation (KDE) plots comparing the model and observations (Fig. 7). These plots are essentially smoothed scatterplots with darker shades representing higher densities of data. Visibility forecast improvement gained by including blowing snow hydrometeors is clearly illustrated in Fig. 7 by comparing the two simulated visibilities against the observed. The centroid of the observed visibility is approximately $2.5 \mathrm{~km}$. In contrast, the centroid of the standard visibility diagnostic is nearly $16 \mathrm{~km}$, indicative of unobstructed visibility. Once blowing snow hydrometeors are incorporated into the visibility equation, the simulated visibility centroid is reduced to approximately $3 \mathrm{~km}$, and the $\mathrm{KDE}$ distribution is near the one-to-one line, indicating substantial improvement.

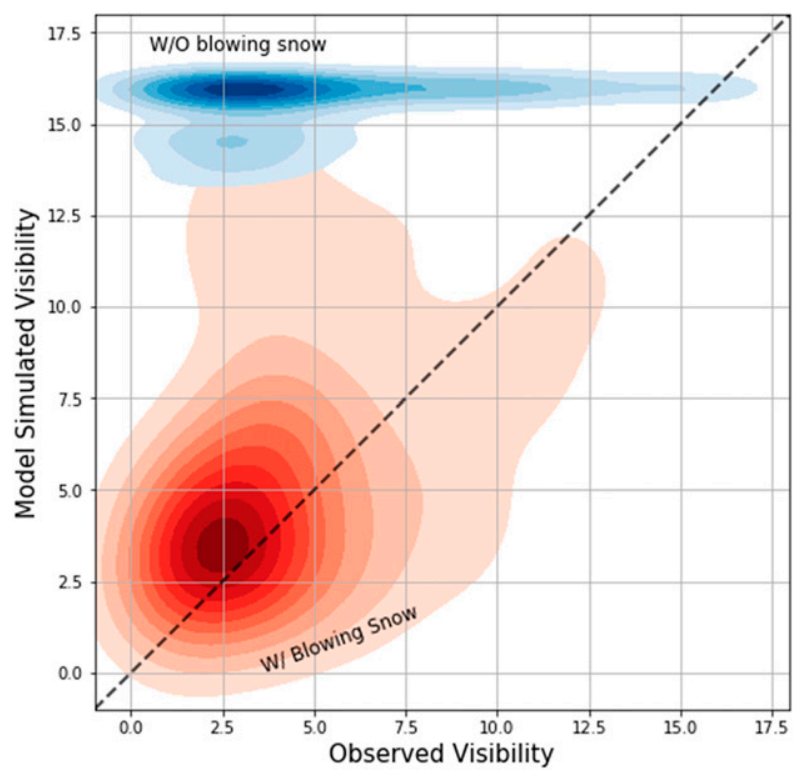

FIG. 7. Kernel density estimation (KDE) figure illustrating the concentration of data between the time-mean observed visibility and model simulated visibility with (red) and without (blue) blowing snow hydrometeors at all stations within the WRF highresolution domain. Time average is between 1200 UTC 24 Feb 2019 and 0000 UTC 25 Feb 2019. The one-to-one line is shown to aid interpretation.

We examine the sensitivity of simulated visibility to moderate changes in the $u_{*_{t}}, \alpha$, and $\bar{r}$ parameters as a means of characterizing uncertainty (Fig. 8). The simulated visibility showed a moderately high sensitivity to $u_{*_{t}}$ and $\bar{r}$, and was largely insensitive to $\alpha$. Unsurprisingly, the lowest $u_{*_{t}}$ value was associated with the lowest simulated visibility, as lower $u_{*_{t}}$ values permit greater blowing snow concentrations in the boundary layer. However, we note that a small increase in $u_{*_{t}}$ of $0.05 \mathrm{~m} \mathrm{~s}^{-1}$ had a negligible impact on the results, and that even when $u_{*_{t}}$ is doubled from the original value of $0.2-$ $0.4 \mathrm{~m} \mathrm{~s}^{-1}$ which is indicative of a dramatic increase in snow surface hardness, there are still significant visibility reductions. We suspect that this sensitivity will be unique to individual events depending on how strong the wind speed is. For example, this case-study was driven by anomalously strong wind speeds (i.e., sustained in exceedance of $13 \mathrm{~m} \mathrm{~s}^{-1}$ across the region), which lowered the effect of increased snow surface hardness on the results.

Simulated visibility was highly sensitive to $\bar{r}$. Specifically, increasing the $\bar{r}$ from 30 to $50 \mu \mathrm{m}$ increased the centroid visibility from approximately 2.5 to $5 \mathrm{~km}$, with no incidences of sub-1-km visibility. Further investigation of this sensitivity is performed by plotting visibility as a function of blowing snow mixing ratio for $\bar{r}=20,30$, and $50 \mu \mathrm{m}$ (Fig. 9). This analysis reveals the influence that $\bar{r}$ has on the relationship between visibility and blowing snow mass concentration, effectively controlling how rapidly the visibility approaches zero as blowing snow concentration increases. That the larger mean radius is unable to produce the whiteout visibilities observed 

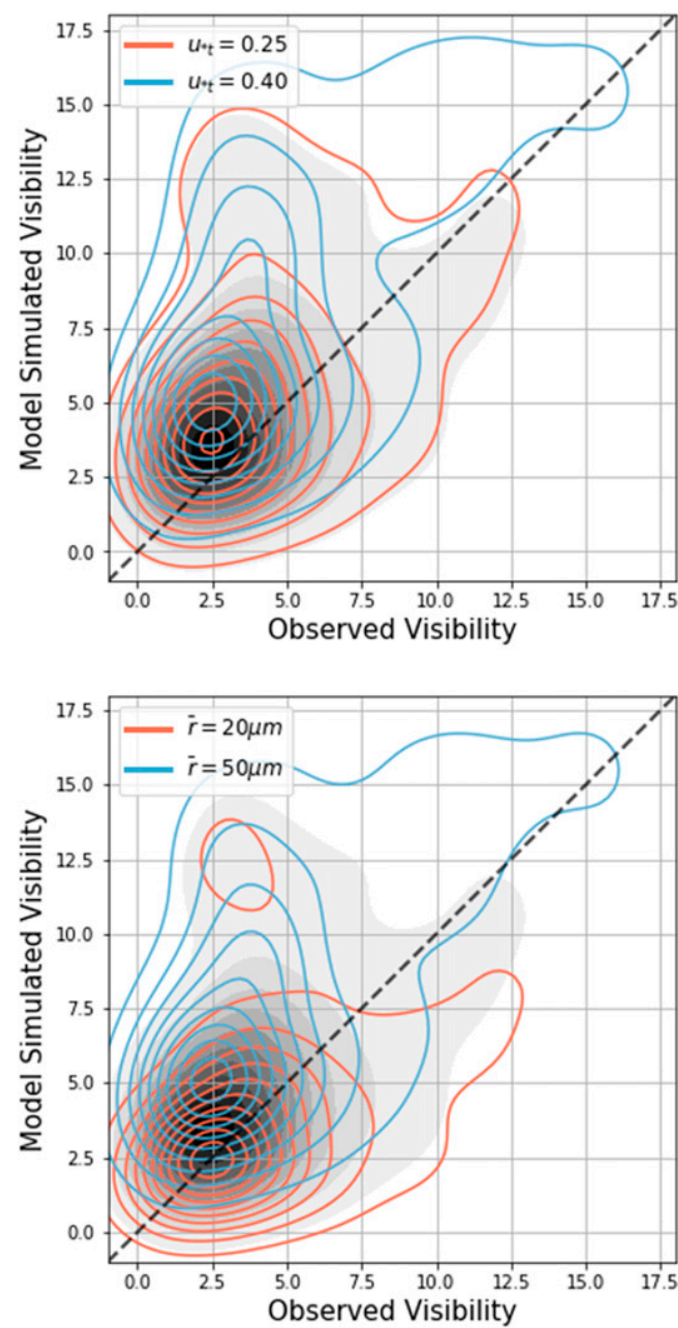

during this event suggests that this framework will, in general, be more accurate when a smaller mean radius is prescribed. However, we are careful to remark that our recommendation to prescribe small particles (i.e., $\bar{r}<35 \mu \mathrm{m}$ ) may be unique to this specific diagnostic framework, since there were no accompanying measurements of blowing snow mixing ratio to evaluate the saltation-through-turbulent suspension pieces of this parameterization.

\section{Discussion}

There remain significant challenges in blowing snow prediction that are largely unaddressed in this parameterization. For instance, while the steady-state assumption is convenient, it is not able to accommodate rapid fluctuations in blowing snow concentration caused by unresolved boundary layer turbulence and wind gusts. Moreover, the steady-state assumption precludes the incorporation of an explicit sublimation term which may limit this model's accuracy under certain atmospheric conditions as sublimation will modify both the blowing snow mass concentration and optical properties. Finally, as part of this case study, we

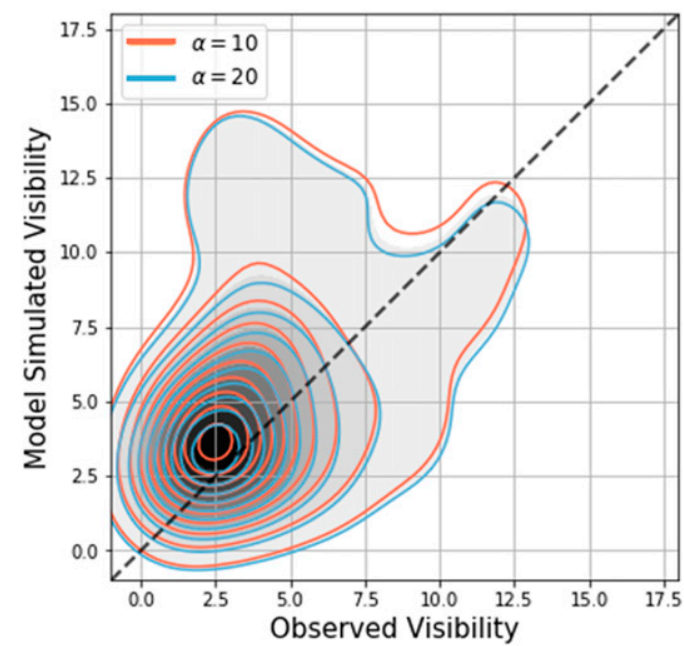

FIG. 8. KDE figures illustrating the sensitivity of time-mean visibility to the $u *_{t}, \alpha$, and $\bar{r}$ parameters. Gray shaded contours show the reference blowing snow visibility from Fig. 7 . The red and blue contours are as indicated in the figure.

neglected to address the snow surface erodibility and $u_{* t}$ parameter in a physically meaningful way by treating it as uniform in time and space. While we argue that such a representation is acceptable for this case study due to the fact that the snow surface was comprised of fresh snow, given the high sensitivity of simulated visibility to variations in $u_{*}$, future validation efforts should treat this parameter in a more robust way. Considering the narrow range of blowing snow concentrations over which visibility transitions from unobstructed to poor (e.g., Fig. 9), uncertainty related to these processes can have a large impact, potentially explaining some of the implied scatter in Fig. 7.

We chose this event as an exemplary case study to demonstrate this parameterization because this was a noteworthy event with a prevalence of unambiguous data. In a majority of instances, however, standard observations are less straightforward to interpret, and looking toward the future, there are significant hurdles related to these data that hinder a robust evaluation of this parameterization over a wider range of blowing snow events. Most notably, it is uncommon for blowing snow be clearly visible in satellite imagery. Even in the absence of overhead cloud cover, these observations can only 


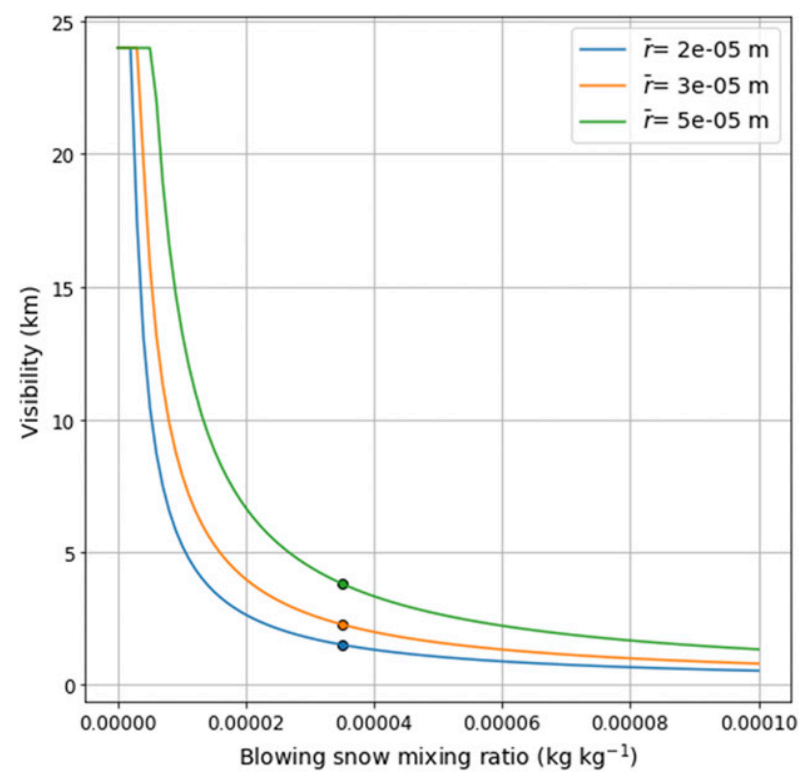

FIG. 9. Visibility computed as a function of blowing snow mixing ratio as determined from Eq. (6), with $\alpha=15$. Markers indicate visibility computed from a blowing snow mixing ratio characteristic of this event.

detect blowing snow during daylight hours and during highest-impact events when blowing snow plumes are optically thick (Kennedy and Jones 2020). Furthermore, analysis presented here strongly suggests that ASOS observations significantly underreport blowing snow, misclassifying it as a different obstruction such as haze or freezing fog. Without accompanying satellite imagery, this shortcoming will complicate future efforts to evaluate this parameterization more broadly using standard automated surface weather observations.

\section{Conclusions}

This paper demonstrates that employing components of physically based snow transport models to diagnose blowing snow visibility impacts from standard NWP output can be used to greatly improve forecasts of blowing snow and its impacts on visibility. Furthermore it demonstrates how GOES-16 false color imagery can be leveraged to qualitatively evaluate simulated blowing snow under certain conditions. This diagnostic overlay is simple to apply to existing NWP output, and can aid in situational awareness in the forecaster community by identifying regions most at risk of blowing snow using physically based methods. This work also serves as an important step toward implementing a blowing snow prognostic variable into a mesoscale atmospheric model by demonstrating that the saltation and turbulent suspension models can accurately simulate blowing snow. We anticipate that this model is broadly applicable to a wide range of blowing snow events due to its foundation in physical processes; however, its accuracy is likely variable from event-to-event. Accordingly, future work should focus on evaluating this framework using additional case studies and on refining and testing parameterizations for the threshold friction speed $u_{*}$.

Acknowledgments. Funding support for this research was provided by the U.S. Army Engineer Research and Development Center (ERDC) Extreme Terrain Research Program, "Forecasting EO/IR Extinction Characteristics for Active and Passive Optical Systems" project under Work Item BK02CH sponsored by the Assistant Secretary of the Army for Acquisition, Logistics, and Technology (ASA-ALT). Any use of trade, product, or firm names is for descriptive purposes only and does not imply endorsement by the U.S. government. Additionally, we thank the anonymous reviewers for providing valuable comments and suggestions to improve the manuscript.

Data availability statement. The surface data analyzed in this study were collected from the Iowa Environmental Mesonet data repository. Further documentation about data processing is available at https://mesonet.agron.iastate.edu/request/ download.phtml. GOES-16 Satellite data were derived from channel radiance data, which are publicly available from the NOAA Comprehensive Large Array Stewardship System (CLASS). Further documentation about CLASS data processing is available at https://www.avl.class.noaa.gov. Surface meteorological weather maps used to qualitatively evaluate the WRF simulation were viewed at the Weather Prediction Center's Surface Analysis Archive, publicly available at https:// www.wpc.ncep.noaa.gov/archives/web_pages/sfc/sfc_archive.php. Rapid Refresh Model data used to initialize and force the WRF Model were ordered from the NOAA Operational Model Archive and Distribution System (NOMADS; Rutledge et al. 2003) Archive Information Request System (AIRS). These data are publicly accessible at https://www.ncdc.noaa.gov/has/. The authors were unable to find a valid public data repository for the WRF Model data generated in this study. These data, along with all accompanying metadata and analysis code are available upon request from Theodore Letcher at CRREL.

\section{APPENDIX}

\section{WRF Module}

While this diagnostic is well suited to work with preexisting model output generated from any numerical model, for convenience, we have developed this diagnostic into a stand-alone WRF module and tested it within the WRF 4.1 EM-CORE. Note that diagnostic is not as part of the current WRF 4.1 baseline release, and requires users to compile additional and replacement Fortran modules as part of their personal WRF build. This diagnostic is implemented in WRF with a series of new namelist options that give users control over the parameters used:

- blowing_snow_diag: namelist flag specifying whether to use the blowing snow diagnostic or not $(1=$ on and $0=$ off $)$;

- blowing_snow_ust: Specified threshold friction speed constant value $\left(\mathrm{m} \mathrm{s}^{-1}\right)$, default $=0.25$; 
- blowing_snow_visz: Height of visibility calculation (m), default $=2.0$

- blowing_snow_rmean: Mean radius of blowing snow particles $(\bar{r} ; \mu \mathrm{m})$, default $=50.0$;

- blowing_snow_alpha: Blowing snow shape parameter for the size distribution $(\alpha)$, default $=12$.

This diagnostic outputs two variables to the WRF history files: BSNOWVIS and BSNOWEXT, representing the visibility calculation computed from Eq. (6), and the blowing snow extinction coefficient computed from Eq. (9). Note that these variables will not be generated if blowing_snow_diag $=0$. Currently, this diagnostic is only available for the EM dynamic core, and was only tested to ensure consistency with the results of this case study. All requisite Fortran files and modifications to the code are available upon request.

\section{REFERENCES}

Anderson, R. S., and B. Hallet, 1986: Sediment transport by wind: Toward a general model. Geol. Soc. Amer. Bull., 97, 523-535, https://doi.org/10.1130/0016-7606(1986)97<523: STBWTA $>2.0 . \mathrm{CO} ; 2$.

Baggaley, D. G., and J. M. Hanesiak, 2005: An empirical blowing snow forecast technique for the Canadian arctic and the prairie provinces. Wea. Forecasting, 20, 51-62, https://doi.org/ 10.1175/WAF-833.1.

Bagnold, R. A., 1941: The Physics of Blown Sand and Desert Dunes. Chapmann and Hall, 322 pp.

Brown, T., and J. Pomeroy, 1989: A blowing snow particle detector. Cold Reg. Sci. Technol., 16, 167-174, https://doi.org/10.1016/ 0165-232X(89)90017-7.

Comola, F., J. F. Kok, J. Gaume, E. Paterna, and M. Lehning, 2017: Fragmentation of wind-blown snow crystals. Geophys. Res. Lett., 44, 4195-4203, https://doi.org/10.1002/2017GL073039.

Déry, S. J., and M. Yau, 1999: A bulk blowing snow model. Bound.Layer Meteor., 93, 237-251, https://doi.org/10.1023/A: 1002065615856.

Gordon, M., and P. A. Taylor, 2009: Measurements of blowing snow, Part I: Particle shape, size distribution, velocity, and number flux at Churchill, Manitoba, Canada. Cold Reg. Sci. Technol., 55, 63-74, https://doi.org/10.1016/j.coldregions.2008.05.001.

He, S., and N. Ohara, 2017: A new formula for estimating the threshold wind speed for snow movement. J. Adv. Model. Earth Syst., 9, 2514-2525, https://doi.org/10.1002/2017MS000982.

Horvath, H., 1967: On the applicability of the Koschmieder visibility formula. Atmos. Environ., 5, 177-184, https://doi.org/ 10.1016/0004-6981(71)90081-3.

Huang, Q., J. Hanesiak, S. Savelyev, T. Papakyriakou, and P. A. Taylor, 2008: Visibility during blowing snow events over arctic sea ice. Wea. Forecasting, 23, 741-751, https://doi.org/10.1175/ 2008WAF2007015.1.

Iacono, M. J., J. S. Delamere, E. J. Mlawer, M. W. Shephard, S. A. Clough, and W. D. Collins, 2008: Radiative forcing by longlived greenhouse gases: Calculations with the AER radiative transfer models. J. Geophys. Res., 113, D13103, https://doi.org/ 10.1029/2008JD009944.

IEM, 2020: Iowa environmental Mesonet ASOS/AWOS surface data. Department of Agronomy, Iowa State University, accessed February 2020, https://mesonet.agron.iastate.edu/ASOS/.

Kain, J. S., 2004: The Kain-Fritsch convective parameterization: An update. J. Appl. Meteor., 43, 170-181, https://doi.org/ 10.1175/1520-0450(2004)043<0170:TKCPAU >2.0.CO;2.
Kang, L. X. Zhou, T. van Hooff, B. Blocken, and M. Gu, 2018: CFD simulation of snow transport over flat, uniformly rough, open terrain: Impact of physical and computational parameters. J. Wind Eng. Ind. Aerodyn., 177, 213-226, https://doi.org/ 10.1016/j.jweia.2018.04.014.

Kennedy, A., and C. Jones, 2020: GOES-16 observations of blowing snow in horizontal convective rolls on 24 February 2019. Mon. Wea. Rev., 148, 1737-1750, https://doi.org/10.1175/ MWR-D-19-0354.1.

Kok, J. F., 2011: A scaling theory for the size distribution of emitted dust aerosols suggests climate models underestimate the size of the global dust cycle. Proc. Natl. Acad. Sci. USA, 108, 10161021, https://doi.org/10.1073/pnas.1014798108.

— E. J. Parteli, T. I. Michaels, and D. B. Karam, 2012: The physics of wind-blown sand and dust. Rep. Prog. Phys., 75, 106901, https://doi.org/10.1088/0034-4885/75/10/106901.

Li, L., and J. W. Pomeroy, 1997: Estimates of threshold wind speeds for snow transport using meteorological data. J. Appl. Meteor., 36, 205-213, https://doi.org/10.1175/1520-0450(1997)036<0205: EOTWSF $>2.0 . C O ; 2$.

Liston, G. E., and M. Sturm, 1998: A snow-transport model for complex terrain. J. Glaciol., 44, 498-516, https://doi.org/ 10.1017/S0022143000002021.

— R. B. Haehnel, M. Sturm, C. A. Hiemstra, S. Berezovskaya, and R. D. Tabler, 2007: Simulating complex snow distributions in windy environments using SnowTran-3D. J. Glaciol., 53, 241-256, https://doi.org/10.3189/172756507782202865.

Mellor, M., 1965: Blowing snow. Monogr. III-A3C, U. S. Army Cold Regions Research Eng. Lab., 79 pp.

Nakanishi, M., and H. Niino, 2009: Development of an improved turbulence closure model for the atmospheric boundary layer. J. Meteor. Soc. Japan, 87, 895-912, https://doi.org/10.2151/ jmsj.87.895.

National Operational Hydrologic Remote Sensing Center, 2004: Snow Data Assimilation System (SNODAS) data products at NSIDC, version 1. National Snow and Ice Data Center, Boulder, CO, https://doi.org/10.7265/N5TB14TC.

NCEI, 2017: NOAA GOES-R series Advanced Baseline Imager (ABI) level 1B radiances. GOES-R calibration working group and GOES-R series program, NOAA National Centers for Environmental Information, accessed February 2020, https:// doi.org/10.7289/V5BV7DSR.

Nemoto, M., and K. Nishimura, 2004: Numerical simulation of snow saltation and suspension in a turbulent boundary layer. J. Geophys. Res., 109, D18206, https://doi.org/10.1029/ 2004JD004657.

Nishimura, K., and M. Nemoto, 2005: Blowing snow at Mizuho Station, Antarctica. Philos. Trans. Roy. Soc. London, 363A, 1647-1662, https://doi.org/10.1098/rsta.2005.1599.

Niu, G.-Y., and Coauthors, 2011: The Community Noah Land Surface Model with Multiparameterization Options (NoahMP): 1. Model description and evaluation with local-scale measurements. J. Geophys. Res., 116, D12109, https://doi.org/ 10.1029/2010JD015139.

Owen, P. R., 1964: Saltation of uniform grains in air. J. Fluid Mech., 20, 225-242, https://doi.org/10.1017/S0022112064001173.

Palm, S. P., Y. Yang, J. D. Spinhirne, and A. Marshak, 2011: Satellite remote sensing of blowing snow properties over Antarctica. J. Geophys. Res., 116, D16123, https://doi.org/ 10.1029/2011JD015828.

Paterna, E., P. Crivelli, and M. Lehning, 2016: Decoupling of mass flux and turbulent wind fluctuations in drifting snow. Geophys. Res. Lett., 43, 4441-4447, https://doi.org/10.1002/2016GL068171. 
Pomeroy, J., and D. Male, 1988: Optical properties of blowing snow. J. Glaciol., 34, 3-10, https://doi.org/10.1017/S0022143000008996.

— 1583-1594, https://doi.org/10.1029/WR026i007p01583.

_- , and D. Male, 1992: Steady-state suspension of snow. J. Hydrol., 136, 275-301, https://doi.org/10.1016/0022-1694(92) 90015-N.

_ D. Gray, and P. Landine, 1993: The prairie blowing snow model: Characteristics, validation, operation. J. Hydrol., 144, 165-192, https://doi.org/10.1016/0022-1694(93)90171-5.

Raupach, M., 1992: Drag and drag partition on rough surfaces. Bound.-Layer Meteor., 60, 375-395, https://doi.org/10.1007/ BF00155203.

Rutledge, G., J. Alpert, R. Stouffer, and B. Lawrence, 2003: The NOAA operational model archive and distribution system (nomads). Realizing Teracomputing, W. Zwieflhofer and N. Kreitz, Eds.,World Scientific, 106-129.

Schmidt, R., 1982: Properties of blowing snow. Rev. Geophys., 20, 39-44, https://doi.org/10.1029/RG020i001p00039.

Skamarock, W. C., and Coauthors, 2019: A Description of the Advanced Research WRF Model version 4. NCAR Tech. Note NCAR/TN-556+STR, 145 pp., https://doi.org/10.5065/ 1 dfh-6p97.
Stoelinga, M. T., and T. T. Warner, 1999: Nonhydrostatic, mesobeta-scale model simulations of cloud ceiling and visibility for an east coast winter precipitation event. J. Appl. Meteor., 38, 385-404, https://doi.org/10.1175/15200450(1999)038<0385:NMSMSO > 2.0.CO;2.

Thompson, G., P. R. Field, R. M. Rasmussen, and W. D. Hall, 2008: Explicit forecasts of winter precipitation using an improved bulk microphysics scheme. Part II: Implementation of a new snow parameterization. Mon. Wea. Rev., 136, 5095-5115, https://doi.org/10.1175/2008MWR2387.1.

Vionnet, V., E. Brun, S. Morin, A. Boone, S. Faroux, P. Moigne, E. Martin, and J. Willemet, 2012: The detailed snowpack scheme Crocus and its implementation in SURFEX v7.2. Geosci. Model Dev., 5, 773-791, https://doi.org/10.5194/gmd-5-773-2012.

—, E. Martin, V. Masson, G. Guyomarc'h, F. Naaim-Bouvet, A. Prokop, Y. Durand, and C. Lac, 2014: Simulation of windinduced snow transport and sublimation in alpine terrain using a fully coupled snowpack/atmosphere model. Cryosphere, $\mathbf{8}$, 395-415, https://doi.org/10.5194/tc-8-395-2014.

Walter, B., C. Gromke, and M. Lehning, 2012: Shear-stress partitioning in live plant canopies and modifications to Raupach's model. Bound.-Layer Meteor., 144, 217-241, https://doi.org/ 10.1007/s10546-012-9719-4. 